Annals of International Medical and Dental Research

E-ISSN: 2395-2822 | P-ISSN: 2395-2814

Vol-8, Issue-1 | January-February 2022

DOI: 10.53339/aimdr.2022.8.1.11

Page no- 81-86 | Section- Research Article (Miscellaneous)

\title{
Assessment of Role of Platelet Aggregation in Metastatic Breast Cancer Patients
}

\section{Ashwini Ramji ${ }^{*}$, Shanmugan C V ${ }^{2}$}

1Assistant Professor, Department of Pathology, PK Das Institute of Medical Sciences, Vaniamkulam, Ottapalam, Kerala, India.

Email: drashwiniwins@gmail.com

Orcid ID: 0000-0001-6078-9590

2Assistant Professor, Department of Medicine, PK Das Institute of Medical Sciences, Vaniamkulam, Ottapalam, Kerala, India.

Email: drcvshanmughan@gmail.com

Orcid ID: 0000-0002-1098-2146

*Corresponding author

Received: 29 September 2021

Revised: 09 November 2021

Accepted: 17 November 2021

Published: 22 December 2021

\begin{abstract}
Background: To assess role of platelet aggregation in metastatic breast cancer patients. Methods: 40 cases (Group I) of metastatic breast cancer patients and equal number of healthy control (Group II) subjects were included. Platelet aggregation studies in vitro using ADP and Thrombin were performed using an optical aggregometer. Detection of platelet aggregation was done by Chrono log series 490 dual and four channel optical aggregometer systems. Results: There were 4 subjects in group I and 12 in group II having ADP $<60,26$ subjects in group I and 28 in group II with ADP 61-72 and 10 subjects in group I with ADP $>72$. Low thrombin $<58$ was seen in 8 in group II, normal thrombin between 61-72 was seen among 11 in group I and 32 in group II and high thrombin $>82$ among 29 in group I respectively. Amongst patients with normal platelet count, 14 patients had platelet aggregation with ADP in the normal range and 4 patients had platelet aggregation with ADP in the lower range. In patients with high platelet count, 12 showed aggregation in the normal range, and 10 patients showed aggregation in the higher range which was statistically significant $(\mathrm{P}<0.05)$ (Table III, Graph II). Conclusion: Platelet aggregation has an important part to play in the tumor metastasis of breast cancer patients.
\end{abstract}

Keywords:- Breast cancer, Platelet aggregation, Tumor metastasis.

\section{INTRODUCTION}

Breast cancer is the most common cancer among females in the world. It has now become the most common female cancer in urban India with an annual incidence of approximately 144,000 new cases being reported.[1,2] Although early detection, precise resection using wide margins and systematic adjuvant therapy has improved survival, distant metastasis remains the leading cause of breast related mortality. [3]
Blood platelets play an important role in hemostasis and arterial thrombosis through their activation triggered by several different agonists. [4] Blood platelets from patients with cancer exhibit a variety of qualitative abnormalities.[5] These include reduced, increased, or spontaneous platelet aggregation and their impaired adhesion, and hypersensitivity to various platelet agonists.6] Besides crucial role of platelets in coagulation and maintaining hemostasis following mechanical injury of the vasculature, platelets contain a plethora of bioactive molecules in 
Annals of International Medical and Dental Research

E-ISSN: 2395-2822 | P-ISSN: 2395-2814

Vol-8, Issue-1 | January-February 2022

DOI: 10.53339/aimdr.2022.8.1.11

Page no- 81-86 | Section- Research Article (Miscellaneous)

their granules and express different receptors on their surfaces that also contribute to inflammation, cancer progression, and metastasis.[] In the initial minutes, when tumor cells detach from the primary tumor and access the blood, platelets are the first host cells they encounter. Circulating tumor cells (CTCs) have been defined as tumor cells circulating in the peripheral blood of patients which shed from either the primary tumor or its metastases. [8] They cause activation of host platelets that leads to shape change, protein release and membrane based changes and further help in promote metastasis. [9,10] Considering this, we selected present study to assess role of platelet aggregation in metastatic breast cancer patients.

\section{MATERIAL AND METHODS}

The present observational study conducted among 40 cases (Group I) of metastatic breast cancer patients of either genders. Enrolment of patients were done after they agreed to participate in the study. Ethical clearance was obtained before starting the study. We selected equal number of healthy control (Group II) subjects also. Inclusion criteria was clinically and histopathologically confirmed metastatic breast cancer patients. Exclusion criteria was patients on chemotherapy and radiotherapy.

Data pertaining to subjects was recorded. Routine clinical details and investigations were performed. Platelet aggregation studies in vitro using ADP and Thrombin were performed using an optical aggregometer. Other parameters like platelet count, histological grade and surrogate molecular classification was also correlated with platelet aggregation. Detection of platelet aggregation was done by Chrono log series 490 dual and four channel optical aggregometer systems. Results of the study was tabulated and assessed using Mann Whitney $\mathrm{U}$ test. $\mathrm{P}$ value less than 0.05 was considered significant.

\section{RESULTS}

There were 4 subjects in group I and 12 in group II having ADP <60, 26 subjects in group I and 28 in group II with ADP 61-72 and 10 subjects in group I with $\mathrm{ADP}>72$. A significant difference was observed $(P<0.05)$ [Table 1 ].

Low thrombin $<58$ was seen in 8 in group II, normal thrombin between 61-72 was seen among 11 in group I and 32 in group II and high thrombin $>82$ among 29 in group I respectively. A significant difference was observed $(\mathrm{P}<0.05)$ [Table 1, Figure 1].

Amongst patients with normal platelet count, 14 patients had platelet aggregation with ADP in the normal range and 4 patients had platelet aggregation with ADP in the lower range. In patients with high platelet count, 12 showed aggregation in the normal range, and 10 patients showed aggregation in the higher range which was statistically significant $(\mathrm{P}<$ 0.05) [Table 3, Figure 2].

Table 1: Comparison of platelet aggregation with ADP in both groups

\begin{tabular}{|l|l|l|l|}
\hline Range & Group I & Group II & P value \\
\hline ADP $<60$ & 4 & 12 & $<0.05$ \\
\hline ADP 61-72 & 26 & 28 & $>0.05$ \\
\hline
\end{tabular}


Annals of International Medical and Dental Research

E-ISSN: 2395-2822 | P-ISSN: 2395-2814

Vol-8, Issue-1 | January-February 2022

DOI: $10.53339 /$ aimdr.2022.8.1.11

Page no- 81-86 | Section- Research Article (Miscellaneous)

$\mathrm{ADP}>72$

10

0

$<0.05$

Table 2: Platelet aggregation with thrombin in both groups

\begin{tabular}{|l|l|l|l|}
\hline Range & Group I & Group II & P value \\
\hline Low thrombin $<58$ & 0 & 8 & $<0.05$ \\
\hline Normal thrombin $61-72$ & 11 & 32 & $<0.05$ \\
\hline High thrombin $>82$ & 29 & 0 & $<0.05$ \\
\hline
\end{tabular}

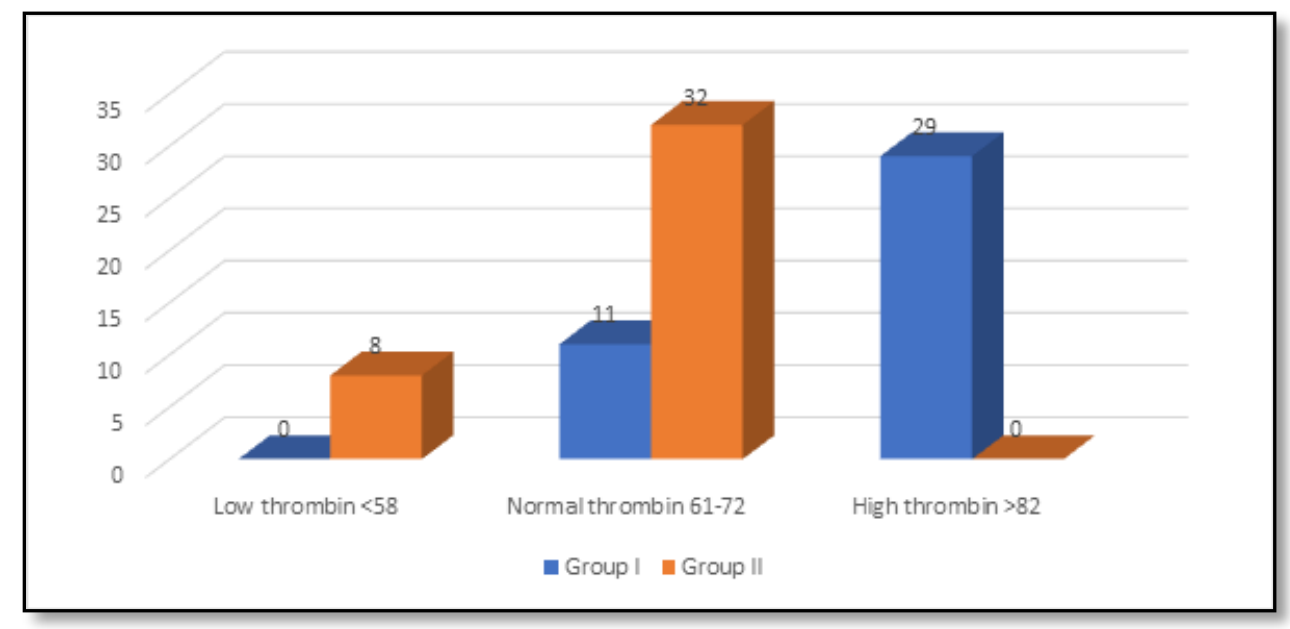

Figure 1: Platelet aggregation with thrombin in both groups

Table 3: Correlation of ADP with platelet count in cases

\begin{tabular}{|l|l|l|l|}
\hline Range & Platelet count 1.5- 4 lac & Platelet count $>$ 4 lac & Total \\
\hline ADP $<60$ & 4 & 0 & 4 \\
\hline ADP 61-72 & 14 & 12 & 26 \\
\hline ADP $>72$ & 0 & 10 & 10 \\
\hline
\end{tabular}




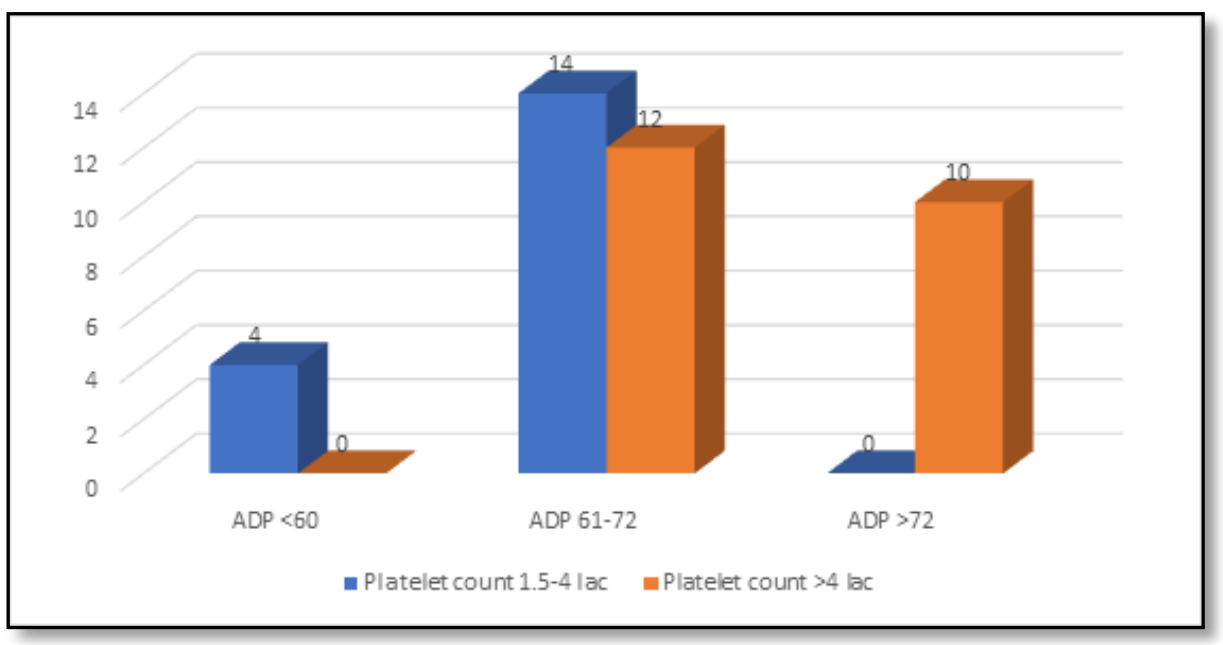

Figure 2: Correlation of ADP with platelet count in cases

\section{DISCUSSION}

In this study role of platelet aggregation in metastatic breast cancer patients were assessed.[11,12] Tumor cells that enter the blood circulation have to cope with high shear rates and the immune surveillance, e.g., the assault of natural killer cells.[13] Only a very small percentage of tumor cells in the circulation ends up in a metastatic foci, making this process very inefficient.[14,15] Platelets protect circulating tumor cells (CTCs) by encasing tumor cells in a thrombus, protecting them from cytolysis by natural killer cells. 16$]$ For a stable adhesion between platelets and tumor cells, tumor cells activate platelets by distinct mechanisms, which are also the reason for hypercoagulation and increased risks of thrombosis in cancer patients. Tumor cells release soluble mediators like ADP, thromboxane A2 (TXA2), or high-mobility group box 1 (HMGB1), which ligates with tolllike receptor 4 (TLR4) to instigate a local platelet activation. [17]

There were 40 breast cancer female patients. Equal number of healthy subjects were taken. There were 4 subjects in group I and 12 in group
II having ADP <60, 26 subjects in group I and 28 in group II with ADP 61-72 and 10 subjects in group I with ADP $>72$. Singla et al, [18] studied the role of platelet aggregation in metastatic breast cancer patients using ADP and thrombin among 30 cases $(n=30)$ of metastatic breast cancer and 30 controls $(n=30)$ of non metastatic breast cancer which were clinically diagnosed and histopathologically confirmed. In this study, increased aggregation was seen with ADP and thrombin in the metastatic cases and none showed increased aggregation in the non metastatic breast cancer patients. Also, high platelet count and higher histological grade correlated with increased aggregation. However, no correlation was seen between platelet aggregation and the surrogate molecular classification.

We observed that low thrombin $<58$ was seen in 8 in group II, normal thrombin between 61-72 was seen among 11 in group I and 32 in group II and high thrombin $>82$ among 29 in group I respectively. Stravodimou et al, $[19]$ showed that patients with thrombocytosis were more likely to have metastases at diagnosis with breast cancer while the normal platelet group was 
Annals of International Medical and Dental Research E-ISSN: 2395-2822 | P-ISSN: 2395-2814 Vol-8, Issue-1 | January-February 2022 DOI: 10.53339/aimdr.2022.8.1.11

Page no- 81-86 | Section- Research Article (Miscellaneous)

more likely to have developed metastatic disease at a time later in the course of the disease. There is a complex interplay between platelets and tumor cells. Thrombocytosis induces formation of large platelet hetero aggregates. These hetero aggregates of platelets and tumor cells can embolize in the microcirculation and aid in the process of extravasation of tumor cells in metastatic sites. Platelets in their granules carry numerous bioactive molecules and growth factors like PDGFa that promotes EMT which gives a mesenchymal phenotype to the epithelial cells that promotes metastasis.

Ward et al,[20] revealed that cancer cellexpressed adhesion GPCR CD97 induced platelet activation which leads to lysophosphatidic acid (LPA) release from platelets. LPA in turn enhances tumor cell invasiveness and vascular permeability to

\section{REFERENCES}

1. Fabre JE, Nguyen M, Latour A, Keifer JA, Audoly LP, Coffman TM, Koller BH. Decreased platelet aggregation, increased bleeding time and resistance to thromboembolism in P2Y1-deficient mice. Nat Med. 1999;5(10):1199-202. doi: 10.1038/13522.

2. Haralabopoulos GC, Grant DS, Kleinman HK, Maragoudakis ME. Thrombin promotes endothelial cell alignment in Matrigel in vitro and angiogenesis in vivo. Am J Physiol. 1997;273(1 Pt 1):C239-45. doi: 10.1152/ajpcell.1997.273.1.C239.

3. Wojtukiewicz MZ, Tang DG, Nelson KK, Walz DA, Diglio CA, Honn KV. Thrombin enhances tumor cell adhesive and metastatic properties via increased alpha IIb beta 3 expression on the cell surface. Thromb Res. 1992;68(3):233-45. doi: 10.1016/00493848(92)90081-k.

4. Zhou H, Gabazza EC, Takeya H, Deguchi H, Urano H, Adachi Y, Suzuki K. Prothrombin and its derivatives promote transendothelial migration. Some cancer cells express tissue factor (TF) on their cell membranes, which activates the plasmatic coagulation cascade and finally generates thrombin which in turn induces platelet activation. Besides the activation of the coagulation cascade and platelets, thrombin is of key importance for almost every step of the metastatic cascade. Thrombin favors tumor cell proliferation and tumor growth, e.g., by activation of PAR-1 and fibrinogen. In tumor microenvironment, thrombin-stimulated fibroblasts and macrophages secrete monocyte chemotactic protein which fosters protumorigenic myeloid cell invasion.

\section{CONCLUSIONS}

It was observed that platelet aggregation has an important part to play in the tumor metastasis of breast cancer patients.

stimulate motility of melanoma cells. Thromb Haemost. 1998;80(3):407-12.

5. Yamahata H, Takeshima H, Kuratsu J, Sarker KP, Tanioka K, Wakimaru N, Nakata M, Kitajima I, Maruyama I. The role of thrombin in the neovascularization of malignant gliomas: an intrinsic modulator for the up-regulation of vascular endothelial growth factor. Int J Oncol. 2002;20(5):9218.

6. Zhou J, Ma X, Bi F, Liu M. Clinical significance of circulating tumor cells in gastric cancer patients. Oncotarget.

2017;8(15):25713-25720. doi:10.18632/oncotarget.14879

7. Lal I, Dittus K, Holmes CE. Platelets, coagulation and fibrinolysis in breast cancer progression. Breast Cancer Res. 2013;15(4):207. doi: 10.1186/bcr3425.

8. Lian L, Li W, Mao Y, Zhang Y, Chen K, Duan W, et al. Inhibition of MCF 7 breast cancer cell induced platelet aggregation using a combination of antiplatelet drugs. Oncol Lett 2013;5:675-80. https://dx.doi.org/10.3892\%2Fol.2012.1074 
Annals of International Medical and Dental Research

E-ISSN: 2395-2822 | P-ISSN: 2395-2814

Vol-8, Issue-1 | January-February 2022

DOI: 10.53339/aimdr.2022.8.1.11

Page no- 81-86 | Section- Research Article (Miscellaneous)

9. Gasic GJ, Gasic TB, Stewart CC. Antimetastatic effects associated with platelet reduction. Proc Natl Acad Sci U S A. 1968;61(1):46-52. doi:10.1073/pnas.61.1.46

10. Alonso-Escolano D, Strongin AY, Chung AW, Deryugina EI, Radomski MW. Membrane type-1 matrix metalloproteinase stimulates tumour cellinduced platelet aggregation: role of receptor glycoproteins. Br J Pharmacol. 2004;141(2):241-252. doi:10.1038/sj.bjp.0705606

11. Jurasz P, Alonso ED, Radomski MW. Platelet cancer interactions: Mechanisms and pharmacology of tumour cell induced platelet aggregation. $\mathrm{Br} \mathrm{J}$ Pharmacol 2004;143:819 26. https://dx.doi.org/10.1038\%2Fsj.bjp.0706013

12. Placke T, Salih HR, Kopp H-G. GITR ligand provided by thrombopoietic cells inhibits NK cell antitumor activity. J Immunol. 2012;189:154-60. https://doi.org/10.4049/jimmunol.1103194

13. Duffau P, Seneschal J, Nicco C, Richez C, Lazaro E, Douchet I, et al. Platelet CD154 potentiates interferonalpha secretion by plasmacytoid dendritic cells in systemic lupus erythematosus. Sci Transl Med. 2010;2:47. https://doi.org/10.1126/scitranslmed.3001001

14. Haselmayer P, Grosse-Hovest L, von Landenberg P, Schild H, Radsak MP. TREM-1 ligand expression on platelets enhances neutrophil activation. Blood. 2007;110:1029-35. https://doi.org/10.1182/blood2007-01-069195

15. Xiang B, Zhang G, Guo L, Li X-A, Morris AJ, Daugherty A, et al. Platelets protect from septic shock by inhibiting macrophage-dependent inflammation via the cyclooxygenase 1 signalling pathway. Nat Commun. 2013;4:2657. https://doi.org/10.1038/ncomms3657

16. Elzey BD, Tian J, Jensen RJ, Swanson AK, Lees JR, Lentz SR, et al. Plateletmediated modulation of adaptive immunity. A communication link between innate and adaptive immune compartments. Immunity. 2003;19:9-19. https://doi.org/10.1016/s1074-7613(03)00177-8

17. Rachidi S, Metelli A, Riesenberg B, Wu BX, Nelson $\mathrm{MH}$, Wallace $\mathrm{C}$, et al. Platelets subvert $\mathrm{T}$ cell immunity against cancer via GARP-TGF $\beta$ axis. Sci Immunol. 2017;2(11):eaai7911. doi: 10.1126/sciimmunol.aai7911.

18. Singla T, Singla G, Ranga S, Singla S, Arora R. Role of platelet aggregation in metastatic breast cancer patients. Indian J Pathol Microbiol 2020;63:564-9. https://doi.org/10.4103/ijpm.ijpm_817_19

19. Stravodimou A, Voutsadakis IA. Pretreatment thrombocytosis as a prognostic factor in metastatic breast cancer. Int J Breast Cancer 2013;2013:289563. https://doi.org/10.1155/2013/289563

20. Ward Y, Lake R, Faraji F, Sperger J, Martin P, Gilliard $\mathrm{C}$, et al. Platelets promote metastasis via binding tumor CD97 leading to bidirectional signaling that coordinates transendothelial migration. Cell Rep. 2018;23:808-22.

https://doi.org/10.1016/j.celrep.2018.03.092

Source of Support: Nil, Conflict of Interest: None declared 